\title{
To understand a journal through four features: An example of Journal of Integrative Cardiology
}

\author{
Chien $\mathrm{T}^{1,2}$, Chang $\mathrm{Y}^{3}$ and Lin $\mathrm{C}^{4 *}$ \\ ${ }^{1}$ Research Departments, Chi-Mei Medical Center, Taiwan \\ ${ }^{2}$ Department of Hospital and Health Care Administration, Chia-Nan University of Pharmacy and Science, Tainan, Taiwan \\ ${ }^{3}$ National Taiwan University School of Medicine, Taiwan \\ ${ }^{4}$ Department of psychiatry, Chi-Mei Medical Center, Taiwan
}

\begin{abstract}
Purpose: Identifying journal features is important and meaningful. However, no journal combines Google map with social network analysis (SNA) to present publication information. Our aims were to visualize the journal characteristics for Journal of Integrative Cardiology (JIC) and presenting resulting findings using SNA.

Methods: Selecting 115 articles on October 21, 2017 from the JIC website, we analyzed author names, keywords, and the corresponding author's nation to report features: (1) article types, (2) nation distribution, (3) the most productive authors and their authorship clusters, and (4) journal main keywords since 2015. We present both a global map with the functionality of a Google Map (zooming, etc.) and network maps based on normalized relations. SNA Pajek software was performed in this study.

Results: We found that (1) the most frequency of types is Research Article (44,38.26\%); (2) the most number of papers are from nations of US (26, 22.6\%), Italy (22, 19.13\%), and Brazil (16, 13.91\%); (3) the most productive authors are Márcio Galindo Kiuchi and Shaojie Chen; (4) the most linked Keywords are blood pressure, heart failure and cardiovascular disease et al.
\end{abstract}

Conclusions: Google map combined with SNA provides wide and deep insight into the relationships among nations, coauthor collaborations, and abstract keywords for JIC. The results can be offered to strategy and decision making for the target journal.

\section{Introduction}

Comorbid is often defined in medicine as existing simultaneously with and usually independently of another medical condition. Cardiovascular comorbidities were common both before and after diabetes [1]. The high comorbidity between psychiatric disorders and cardiovascular disease has received increasing attention recently [2]. In many situations, it is very hard to observe the association of two or more symptoms at one moment.

An apocryphal story often told to illustrate the concept of cooccurrence is about beer and diaper sales. It usually goes along with both beer and diaper sales which were strongly correlated [3-5] in a market place. As such, all possible pairs of our observed phenomena can be combined and analyzed using computer techniques. However, we have not seen any computer algorithms that help us selecting the most possible pairs co-occurred with each other.

\section{Social network analysis (SNA)}

Social network analysis (SNA) [6-8] has applied to authorship collaboration in recent years. It is because co-authorship among researchers that forms a type of social network, called co-author network [7]. We are thus interested in using SNA to explore the most pair relations (e.g., beer and diaper in marking sales) for a journal through what we observed and collected from data, such as abstract keywords, coauthor collaborations, and others related to the target journal, especially using Google map to present these features.
Authors are usually required to provide three to ten key words that represent the main content of the article for an article [9-13]. Keywords or short phrases published with an abstract can assist indexers in crossindexing the article. However, few study investigated whether keywords are substantially associated with the abstract and what keywords that can represent the researched journal in academics.

\section{Author collaborations and international relations}

Many papers have been collected and saved online on website. We have seen some computer scientists placing high hope on those machine-learning algorithms, data mining or artificial intelligence(AI) to quantify research information $[14,15]$ for use in academics. Accordingly, it is possible for us to apply those data and related techniques to understand the features of a specific journal.

For the reason that using internet information is increasing the yield of knowledge from data generated in the course of inquiry [16-

Correspondence to: Chien-Ho Lin, Associate Professor, Medical Research Department, Chi-Mei Medical Center, Taiwan; E-mail: alho@mail.chimei.org.tw

Key words: abstract keywords, authorship collaboration, Google map, social network analysis, Journal of Integrative Cardiology

Received: October 10, 2017; Accepted: October 28, 2017; Published: October 31,2017 
18]. How to further display and develop new knowledge for a target journal is required to explore and further study.

\section{Aims of the study}

Our aims are to investigate journal features of Journal of Integrative Cardiology (JIC) in following topics: (1) article types, (2) nation distribution, (3) the most productive authors and their authorship clusters, and (4) journal main keywords since 2015.

\section{Methods}

\section{Data sources}

We downloaded data including author names, keywords, and the corresponding author's nation from the website of JIC on October 21, 2017 at https://www.oatext.com/Journal-of-Integrative-CardiologyJIC.php\#Archive. Microsoft Excel VBA (visual basic for applications) modules were programed by authors to organize data for use in this study. A total of $115 \mathrm{JIC}$ articles were retrieved.

\section{Data arrangement to fit SNA requirement}

Prior to visualize representations of research findings using SNA, we should organize data in compliance with the SNA format and guidelines using Pajek software [19]. Microsoft Excel VBA was used to arrange data fitting the SNA requirement. For more information about the data format, see Pajek guideline at http://vlado.fmf.uni-lj.si/pub/ networks/pajek/.

\section{Graphical representations to report}

\section{Article types}

Many article types are categorized in JIC, such as Case Report, Review Article, and Short Communication, et al. We recorded the type for each article and made a table to present the first journal feature.

\section{Author nations and their relations} nation.

Google map is suitable for presenting the author distribution by

\section{The most productive authors and their authorships}

Coauthor collaborations for JIC can be drawn using SNA combined by Google map. Their bubbles are sized by the number of paper publication, colored by cluster, and the lines are connected with the chance of co-authorship. Through which, we selected the most productive authors who published the most number of papers in JIC with their colleagues.

\section{Keywords to present the journal research domain}

If keywords represent the research domain for JIC, the stronger relations between two keywords can be highlighted through the SNA on Google map, like the concept of co-occurrence about beer and diaper sales. The presentation for the bubble and line is interpreted similar to the previous section.

\section{Statistical tools and data analyses}

SNA Pajek software [19] was used to obtain the measures of centrality. Google map was applied to display visualized representations for JIC features. Author-made Excel VBA modules were prepared for organizing data.

\section{Results}

\section{Article types}

All 115 JIC papers since 2015 are categorized in Table 1. The most frequency of types is Research Article (44, 38.26\%). Case Report (25, 21.74\%) and Review Article (14, 12.17\%) are following (Table 1).

\section{Author nations and their relations}

Corresponsive authors' nations of JIC are distributed in Figure 1. We can see the top 3 nations are U.S (26, 22.6\%), Italy (22, 19.13\%), and Brazil $(16,13.91 \%)$. The diagram shown in Figure 1 presents author location among nations based on JIC publication. The bigger bubble represents the more number of papers published in the past 3 years (Figure 2).

\section{The most productive authors and their authorships}

The top 2 productive authors (including coauthors in papers) are listed as the two: Márcio Galindo Kiuchi and Shaojie Chen with a big bubble size and a wider connected line (Figure 3).

\section{Keywords to present the journal research domain}

The most linked Keywords are blood pressure, heart failure and cardiovascular disease, et al. (Figure 4). We can see that many bigger bubbles with wider connection lines are shown in the left bottom side of Figure 4, indicating they are commonly co-occurred and discussed in JIC papers.

\section{Discussion}

This study combined Google map with SNA to demonstrate that (1) the most frequency of types is Research Article (44, 38.26\%); (2) the most number of papers are from nations of US $(26,22.6 \%)$, Italy $(22,19.13 \%)$, and Brazil $(16,13.91 \%)$; (3) the most productive authors are Márcio Galindo Kiuchi and Shaojie Chen; (4) the most linked Keywords are blood pressure, heart failure and cardiovascular disease, et al.

\section{What this adds to what was known}

Many previous researches [6-8] have investigated coauthor collaboration using SNA. An apocryphal story often told to discover

Table 1. Article types of Journal of Integrative Cardiology

\begin{tabular}{|l|c|c|}
\hline Article type & Frequency & $\mathbf{\%}$ \\
\hline Research Article & 44 & 38.26 \\
\hline Case Report & 25 & 21.74 \\
\hline Review Article & 14 & 12.17 \\
\hline Short Communication & 9 & 7.83 \\
\hline Mini Review & 7 & 6.09 \\
\hline Editorial & 3 & 2.61 \\
\hline Commentary & 2 & 1.74 \\
\hline Research Article & 2 & 1.74 \\
\hline Case Study & 1 & 0.87 \\
\hline Editorial- & 1 & 0.87 \\
\hline Editorial & 1 & 0.87 \\
\hline Letter to Editor & 1 & 0.87 \\
\hline Opinion Article & 1 & 0.87 \\
\hline Perspective & 1 & 0.87 \\
\hline Retrospective Study & 1 & 0.87 \\
\hline Short Communication- & 1 & 0.87 \\
\hline Update & 1 & 0.87 \\
\hline Total & 115 & 100.00 \\
\hline
\end{tabular}




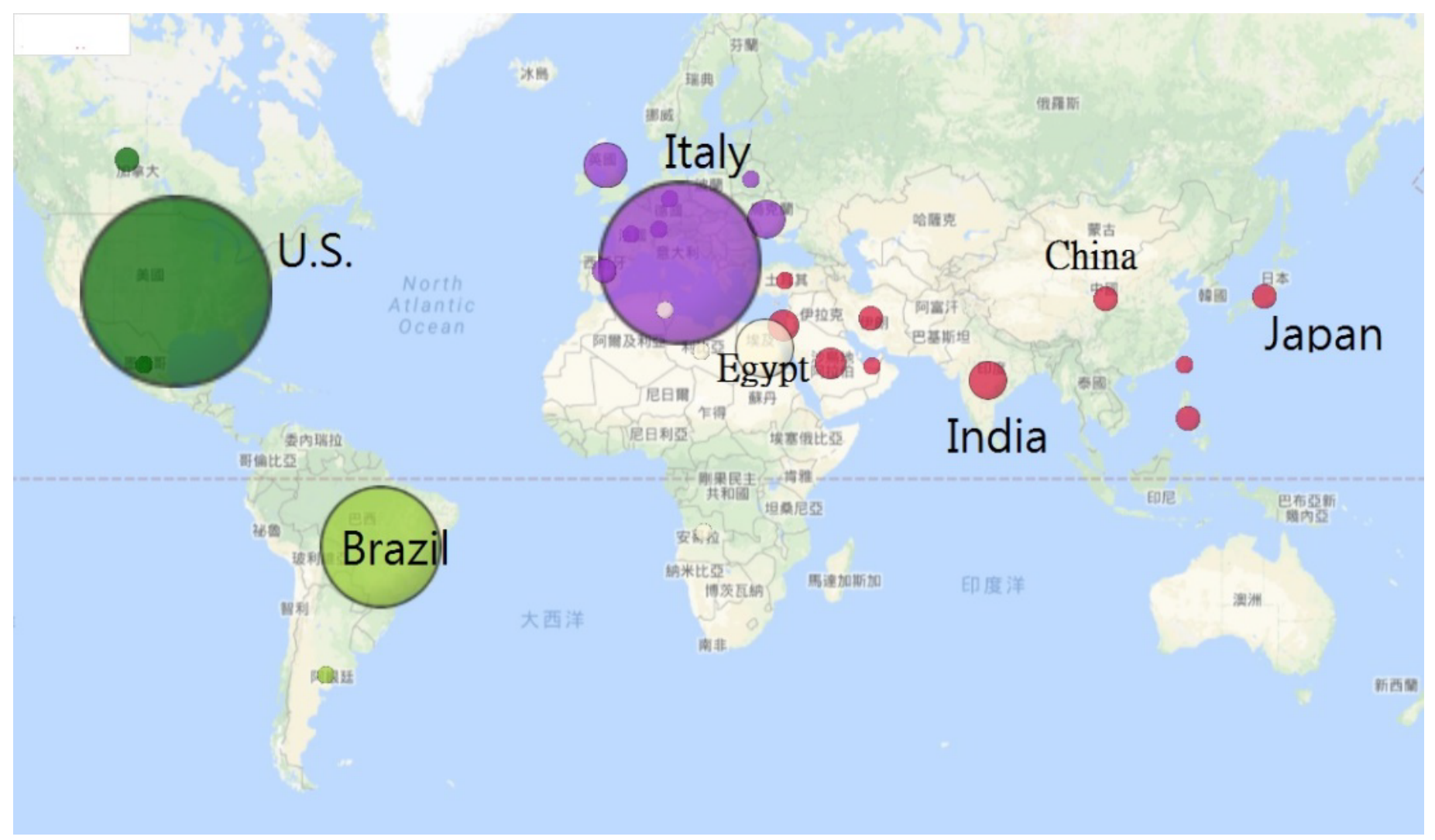

Figure 1. Corresponsive authors' nations for the Journal of Integrative Cardiology.

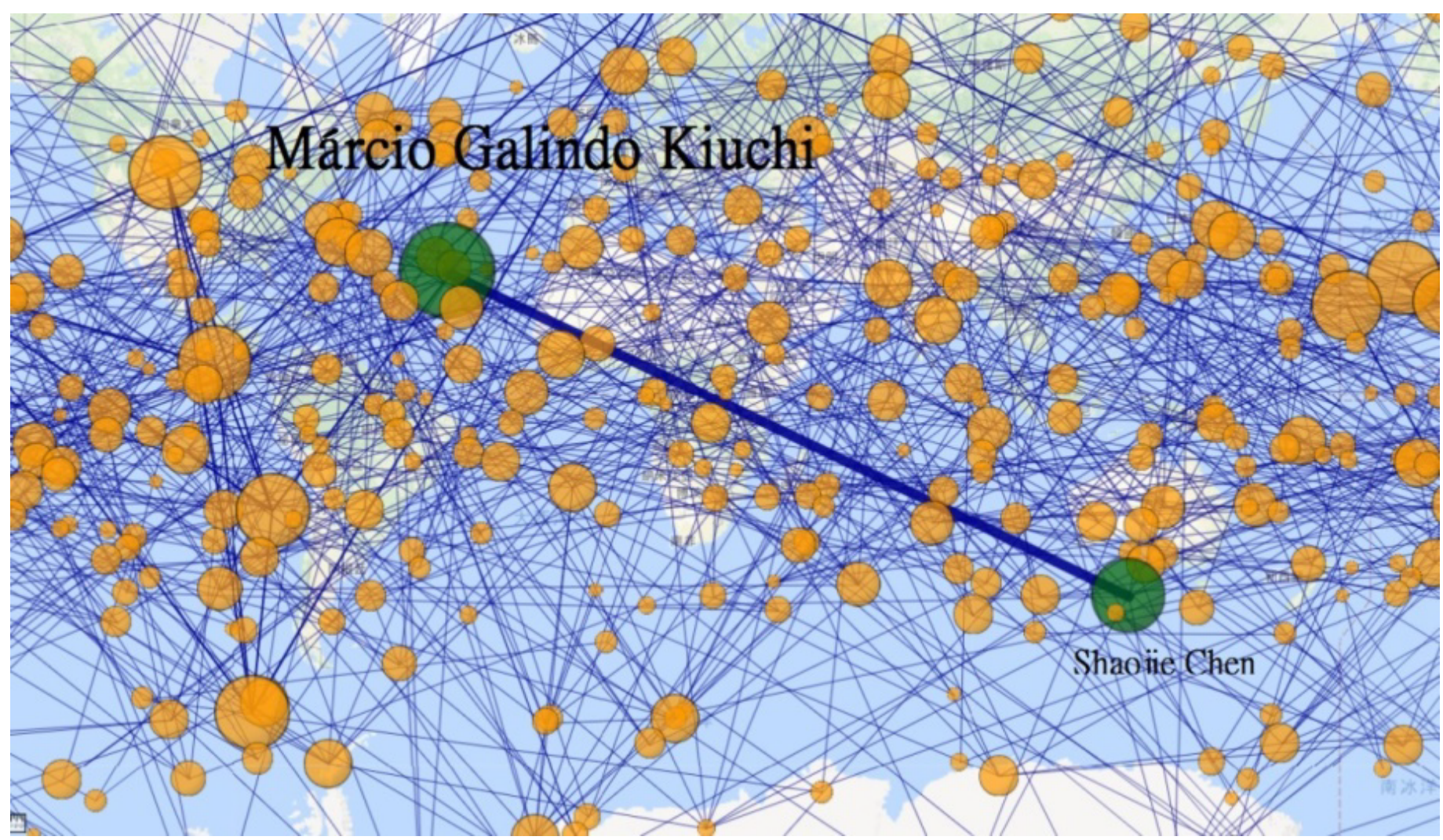

Figure 2. The most productive authors are the two with a green color. 


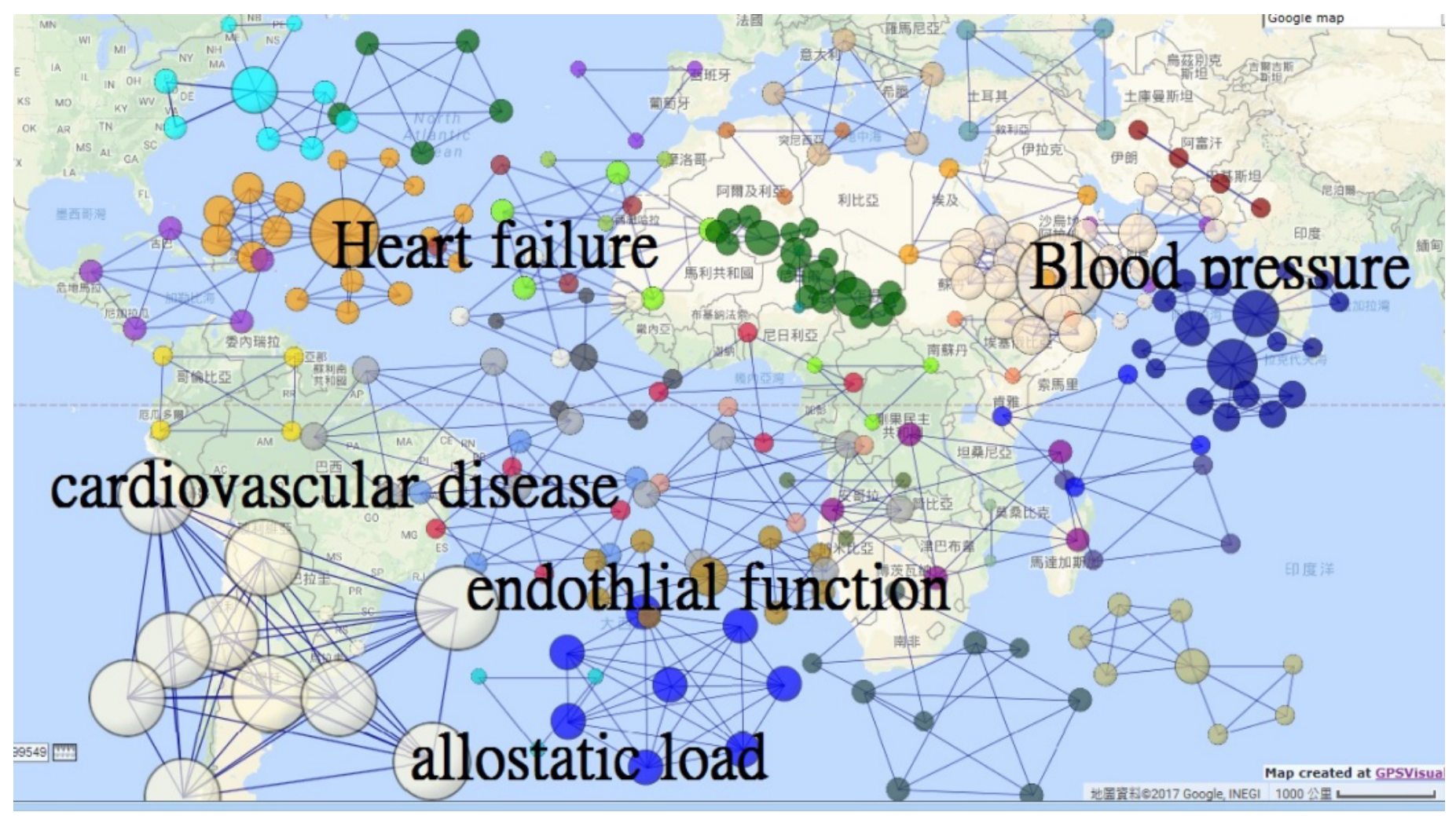

Figure 3. Keyword relations on a Google map.

the co-occurrence about beer and diaper sales [3-5]. However, we have not seen any that can demonstrate a concrete way to show how to conduct this exploration (or, say, how to dance on data) and to present informative messages to readership. We showed how easy the SNA can display all possible pairs of our observed phenomena at a short time using the free-charged Pajek software.

Journal authorship collaboration can be compared with each other (Figure 2). We can see that the author-pattern was the prevailing pattern which is similar to the previous study [6]. Hence the JIC researchers have good collaboration in the subject category of cardiology which is consistent with the previous studies that investigated scientific collaboration of Iranian Psychology and Psychiatry Researchers [20,21].

There are two papers $[22,23]$ incorporated $\mathrm{MeSH}$ (medical subject headings) into social network analysis to explore interesting journal knowledge, but failed to demonstrated it in detail or using Google map, like we did in this study. The way we illustrated the strongest relation in all possible couples of interest is novel and promising in future, especially in the field of bibliometrics and medicine researches.

\section{What it implies and what should be changed?}

Scientific publication is one of the objective measurements to evaluate the achievements of a medical specialty or discipline [22]. Since the advent of bibliometrics, citation analysis has been widely used in many disciplines to evaluate the influence of academic articles [2331]. It is worth using SNA, especially incorporating with Google map, to report journal features in future.

Several algorithms and measures have been developed and used with SNA to graphically explore data. If we investigate whether any author or paper most fits the research domain of a journal and its scope within the journal's keyword network, the centrality measures using
SNA can be applied [6]. It means that the core subject can be analyzed using the centrality measure $[7,8]$ yielded in SNA.

\section{Strengths of this study}

Incorporating Google map with SNA is the strength of this study. The nation distribution in Figure 1 is merit in easily understanding the feature of international collaborations for the journal. Most authors of JIC come from U.S., Brazil, and Italy, see the bigger cluster in Figure 1. Authors from Australia are not seen any published in JIC till now. One picture is worth ten thousand words. We hope following studies can report more such kinds of information using SNA and Google map to readers in future.

\section{Limitations and future study}

The interpretation and generalization of the conclusions of this study should be carried out with caution. First, the data of this study were collected from JIC website. It is worth noting that any attempt to generalize the findings of this study should be made in the similar journal domain with similar topic and scope contexts. Second, although the data were extracted from JIC website and carefully dealt with every linkage as correct as possible, the original downloaded text file including some errors in name of nation because some were not listed with the nation under the corresponding author name. That might lead to some bias in the resulting nation distribution even if we have made great efforts in search of nation name using other relevant information such as the institute name. Third, there are many algorithms used for SNA. We merely applied centrality measure to present the prestigious feature. Any changes made along with algorithm used will present different pattern and judgment. Fourth, the social network analysis is not subject to the Pajeck software we used in this study, Others such as Ucinet [32] and Gephi [33] are suggested to readers for use in 
future. Fifth, all Google maps are shown in the language based on the user's location. Although the Chinese characters are shown in figures, interested readers can use the linkage in references [34-36] to practice it with their own language shown on Google map.

\section{Conclusion}

Social network analysis provides wide and deep insight into the relationships among nations, coauthor collaborations, and abstract keywords related to JIC. The results can be offered to strategy and decision making for the target journal.

\section{References}

1. Robbins JM, Webb DA, Sciamanna CN (2005) Cardiovascular comorbidities among public health clinic patients with diabetes: the Urban Diabetics Study. BMC Public Health 5: 15 .

2. Larsen BA, Christenfeld NJS (2009) Cardiovascular disease and psychiatric comorbidity: the potential role of perseverative cognition. Cardiovasc Psychiatry Neurol 2009: 791017. [Crossref]

3. Domingos P (2012) A few useful things to know about machine learning. Commun ACM 55: 78-87.

4. Verhoef PC, Kooge E, Walk N (2016) Creating Value with Big Data Analytics: Making Smarter Marketing Decisions. London: Routledge.

5. Power DJ (2017) What is the "true story" about data mining, beer and diapers? 3: 23.

6. Sadoughi F, Valinejadi A, Shirazi MS, Khademi R (2016) Social Network Analysis of Iranian Researchers on Medical Parasitology: A 41 Year Co-Authorship Survey. Iran J Parasitol 11: 204-212. [Crossref]

7. Osareh F, Khademi R, Rostami MK, Shirazi MS (2014) Co-authorship Network Structure Analysis of Iranian Researchers' scientific outputs from 1991 to 2013 based on the Social Science Citation Index (SSCI). Collnet J Scientometr Info Manag 8: 263-271.

8. Liu X, Bollen J, Nelson ML, Van de Sompel H (2005) Co-authorship networks in the digital library research community. Info Process Manag 41: 1462-1480.

9. International Committee of Medical Journal Editors (1997) Uniform Requirements for Manuscripts Submitted to Biomedical Journals. N Engl J Med 336: 309-316.

10. IEL (Inderscience Enterprises Ltd) (2015) Keyword requirements.

11. Nadim A (2005) How to Write a Scientific Paper? Ain Shams J Obst Gynecol 2: 256-258.

12. Rhodes W (2010) Guest Editorial: The Abstract as a Marketing Tool. Opt Eng 49: 7.

13. Day R, Gastel B (2006) How to Write and Publish a Scientific Paper. $6^{\text {th }}$ Edition. Westport, Connecticut: Greenwood Press.

14. Luo L, Li L, Hu J, Wang X, Hou B, et al. (2016) A hybrid solution for extracting structured medical information from unstructured data in medical records via a doublereading/entry system. BMC Med Inform Decis Mak 16: 114. [Crossref]

15. Knoblock CA, Lerman K, Minton S, Muslea I (2003) Accurately and reliably extracting data from the web: a machine learning approach. In: Intelligent exploration of the web. New York: Springer 275-287.

16. Ohno-Machado L (2017) Advancing healthcare and biomedical research via new datadriven approaches. J Am Med Inform Assoc 24: 471.

17. Ohno-Machado L (2016) Data-driven informatics tools targeting patients and providers. J Am Med Inform Assoc 23: 1039. [Crossref]
18. Shah NH, Tenenbaum JD (2012) The coming age of data-driven medicine: translational bioinformatics' next frontier. J Am Med Inform Assoc 19: e2-e4. [Crossref]

19. de Nooy W, Mrvar A, Batagelj V (2011) Exploratory Social Network Analysis With Pajek: Revised and Expanded, $2^{\text {nd }}$ edn. New York, NY: Cambridge University Press.

20. Erfanmanesh MA, Rohani VA, Basirian JR, Gholamhosseinzadeh Z (2014) Investigating Scientific Collaboration of Iranian Psychology and Psychiatry Researchers. J Info Process Manag 29: 137-163.

21. Osareh F, Norouzi CA, Keshvari M (2010) Co-authorship of Iranian researchers in science, social science, art and humanities citation indexes in the web of science between 2000 and 2006. J Info Sci Technol 25: 573-595.

22. Chang HT, Lin MH, Hwang IH, Chen TJ, Lin HC, et al. (2017) Scientific publications in gastroenterology and hepatology in Taiwan: An analysis of Web of Science from 1993 to 2013. J Chin Med Assoc 80: 80-85. [Crossref]

23. Hu SK, Huang J, Hong WD, Du XJ, Jin R, et al. (2017) The 50 Most-cited Articles in Gastroenterology and Hepatology from Mainland China. Pak J Med Sci 33: 215-220. [Crossref]

24. Coelho DH, Edelmayer LW, Fenton JE (2014) A century of citation classics in otolaryngology-head and neck surgery journals revisited. Laryngoscope 124: 13581362. [Crossref]

25. Baltussen A, Kindler CH (2004) Citation classics in critical care medicine. Intensive Care Med 30: 902-910. [Crossref]

26. Brandt JS, Downing AC, Howard DL, Kofinas JD, Chasen ST (2010) Citation classics in obstetrics and gynecology: the 100 most frequently cited journal articles in the last 50 years. Am J Obstet Gynecol 203: 355.e1-7. [Crossref]

27. O'Sullivan KE, Kelly JC, Hurley JP (2015) The 100 most cited publications in cardiac surgery: a bibliometric analysis. Irish J Med Sci 184: 91-99. [Crossref]

28. Kelly JC, Glynn RW, O’Briain DE, Felle P, McCabe JP (2010) The 100 classic papers of orthopaedic surgery: a bibliometric analysis. J Bone Joint Surg Br 92: 1338-1343. [Crossref]

29. Kavanagh RG, Kelly JC, Kelly PM, Moore DP (2013) The 100 classic papers of pediatric orthopaedic surgery: a bibliometric analysis. J Bone Joint Surg Am 95: e134. [Crossref]

30. Pagni M, Khan NR, Cohen HL, Choudhri AF (2014) Highly cited works in radiology: the top 100 cited articles in radiologic journals. Acad Radiol 21: 1056-1066. [Crossref]

31. Cao F, Li J, Li A, Fang Y, Li F (2012) Citation classics in acute pancreatitis. Pancreatology 12: 325-330. [Crossref]

32. Borgatti SP, Everett MG, Freeman LC (2002) Ucinet for Windows: Software for Social Network Analysis. Harvard, MA: Analytic Technologies.

33. Bastian M, Heymann S, Jacomy M (2009) Gephi: an open source software for exploring and manipulating networks. International AAAI Conference on Weblogs and Social Media.

34. Chien TW (2017) Corresponsive authors' nations for the Journal of Integrative Cardiology. Retrieved at http://www.healthup.org.tw/gps/integrative.htm

35. Chien TW (2017) The most productive authors are the two with a green color Retrieved at http://www.healthup.org.tw/gps/author.htm

36. Chien TW (2017) Keyword relations on a Google map. Retrieved at http://www. healthup.org.tw/gps/keyword.htm

Copyright: (C2017 Chien T. This is an open-access article distributed under the terms of the Creative Commons Attribution License, which permits unrestricted use, distribution, and reproduction in any medium, provided the original author and source are credited. 